\title{
LA ENSEÑANZA DE LA HISTORIA ANTIGUA EN EL NACIONALISMO ACTUAL DE ANDALUCÍA
}

\author{
The Teaching of Ancient History Current Nationalism in Andalusia
}

\author{
Marco Almansa Fernández \\ Universidad Autónoma de Madrid \\ E-mail: mitologo_85@hotmail.com
}

Fecha de recepción: 6-III-2011

Fecha de aceptación: 25-III- 2011

\begin{abstract}
RESUMEN: La presentación de este trabajo -que entendemos novedoso en tanto no ha sido aún estudiado-, responde a la motivación por mostrar las paradojas que en algunas Comunidades Autónomas (siendo en este caso estudiado el de Andalucía) con las que se encuentra un estudiante de la ESO. No pretende ser más que un ejercicio de lectura comprensiva que intenta dar cuenta de que la historia está escrita, y se reescribe, con unos fines concretos; objetivos marcados por los caracteres nacionalistas e incluso regionalistas. Con ello no queremos, en ningún modo, desautorizar las ideas presentadas en los actuales libros de texto, cuyos contenidos generales son estimables.
\end{abstract}

Palabras clave: Andalucía, educación, historia antigua, nacionalismo, E.S.O.

AвSTRACT: This paper, which is a new subject of study, shows the paradoxes that ESO students find themselves in some Spanish provinces (in the case of Andalusia). It is a comprehensive reading exercise which will demonstrate that history is written, and rewritten, with specific objectives; objectives marked by nationalist and even regionalist tones. It is not our intention, in any way, to undermine the authority of the ideas presented in the actual text books, whose general content is accepted.

Keywords: Andalusia, education, ancient history, nationalism, E.S.O.

El presente proyecto es un esbozo de lo que en tiempos futuros será forjado con mayor desarrollo en un nuevo trabajo doctoral, que comprenderá la utilización de la historia antigua en el nacionalismo actual de Andalucía. El 
capítulo que aquí nos compete es parte de un todo ${ }^{1}$. Por ello, trataremos de forma sucinta la utilización que ciertos ideales reflejan en la educación de la asignatura de Historia en la E.S.O. en la Andalucía actual.

Debemos, por tanto, acercarnos a las fuentes de las que disponemos. Afortunadamente hemos podido abordar todas ellas ya que, a diferencia de otros temas de la Historia Antigua en los que las fuentes son parcas en cantidad, en nuestro caso son abundantes. No obstante, nuestras fuentes primarias serán los propios libros de texto y el objetivo de este trabajo consistirá en hacer un análisis de lo que aparece reflejado en dichos libros de texto. Es decir, de cómo una ideología se implanta de forma tan arraigada en la sociedad, impregnando la educación hasta el límite de un adoctrinamiento distanciado del rigor histórico.

En nuestro objeto de estudio, la historia antigua en los libros de textos andaluces, tendremos en cuenta algunas publicaciones sobre el tema. Aunque poco tratada, a partir de los análisis de Hijano (2000 y 2002)², Ruiz Morales, F.C. $(1999)^{3}$ y Lacomba $(1987)^{4}$ se nos trata de dar una imagen de Andalucía en su conjunto, tanto de su cultura como de su historia, pero la dificultad que nos encontramos es que tales autores tratan los libros de texto de Secundaria y Bachillerato anteriores al 2007 y no los posteriores, fecha significativa puesto que es el año que se aprueba el Estatuto de Andalucía. No obstante, en nuestro caso, sobrepasaremos esa fecha y trataremos de ir más allá.

No es difícil imaginar por donde van las ideas en cuanto a la tergiversación en los libros de texto. Nos referimos a cuán modificado de forma consciente está el contenido de aquellos manuales de secundaria en Andalucía, igual que pasa en otras regiones españolas con una afanosa tendencia nacionalista, como son Cataluña, País Vasco o Galicia. Andalucía parece no querer quedarse atrás en ese constante movimiento educativo influenciado por el crecimiento político-romántico del nacionalismo actual.

Andalucía, a diferencia de las demás regiones con un patriotismo arraigado, carece de un empuje fuerte y concreto en el contexto de los idearios

1 "Uso y abuso de la Historia Antigua en los nacionalismos actuales: el caso de Andalucía" Dirigida por Mora Rodríguez, G. (UAM) y Codirigida por Álvarez Martí-Aguilar, M. (UMA).

2 HIJANO DEL RÍO, M.: "La Historia de Andalucía en los libros de texto", en PORRAS BLANCO, J. (coord.) Independencia, No 39. Mijas (Málaga) 2002.

La Cultura Andaluza en la escuela, Málaga, Sarriá, 2000.

3 RUIZ MORALES, F.C., "La imagen de Andalucía en los libros de texto", en Actas del VII Congreso sobre el andalucismo histórico, Sevilla, Fundación Blas Infante, 1999, pp. 619-636.

4 LACOMBA, J.A., La creación de una disciplina autónoma de Historia y Cultura de Andalucía en el BUP. Un proyecto de didáctica de la asignatura, Ponencia expuesta en el VI Coloquio Metodológico-didáctico, Sevilla, Hespérides, 1987. 
revolucionarios nacionalistas. Mientras que Cataluña y País Vasco están a la cabeza de estos movimientos, y ya ostentan una "historia nacionalista" a sus espaldas, Andalucía tiende a exagerar sus argumentos, sobre todo históricos, para igualarse a las otras dos regiones. De tal forma implanta, de manera similar a Cataluña y País Vasco o Galicia, una educación aplicada en sostener una ideología destinada a los nuevos escolares con la pretensión de obtener una alta consciencia andalucista. Sabemos que, para tal logro, es necesario el afianzamiento de la unidad y, sobre todo, forzar un origen como pueblo.

Deberemos tener en cuenta qué entendemos por adoctrinar, mediante la enseñanza, puesto que es el principio de toda educación propuesta a enseñar a una juventud de forma determinada, con unos pensamientos o ideas, en este caso, nacionalistas.

"La formación hace referencia a las acciones combinadas de suministrar información de carácter científico y cultural y de incitar al ejercicio de la capacidad racional aplicada al análisis crítico de la información recibida. Por su parte, el adoctrinamiento hace referencia a la acción de inculcar doctrinas mediante la presión psíquica ejercida por la autoridad de quien las presenta, al margen de que se correspondan o no con auténticas realidades"

"Es considerado como un método autoritario, algunos filósofos han negado que sea un método de enseñanza y lo han tomado como una educación no normativa donde el alumno no es sometido a un razonamiento lógico, generalmente es memorístico y no se llega a profundizar o hacer suyo un concepto, otros lo toman como un método en el que se pretende que todo sea aceptado sin cuestionamientos, sean verdades o falsedades, por lo cual, las personas que sostienen convicciones religiosas firmes podrían apoyar el adoctrinamiento en el sentido de creer sin cuestionar y los políticos lo apoyan en el sentido de que sea verdad o falsedad, se debe apoyar"6.

Como vemos el adoctrinamiento que se produce en la forma teórica de los libros escolares es patente. Para observarlo in situ es mejor que nos acerquemos a los de texto para comprobar que la intención de hacer una historia diferente es perceptible. Para ello disponemos de ejemplos en muchos libros de texto, pero comenzaremos por el de $1^{\circ}$ de E.S.O., de la editorial Vicens-Vives ${ }^{7}$.

Los libros de texto tienen una estructura de presentación, según los temas que se den. Nosotros nos centraremos en la Andalucía prerromana y, durante la romanización, hasta la aparición del Al-Ándalus, de tal forma que

5 GARCÍA NINET, A. "Educación y adoctrinamiento", Periódico Levante, Valencia, 11 de marzo de 2006.

6 MOORE, T. W. "Introducción a la Filosofía de la Educación" Cap. 4.- Enseñanza y Educación. Ed.Trillas. 1987. p. 59-74.

7 ALBET, A.; BENEIAM, P.; MONTERO, C.; GARCÍA, M.; GATELL, C.; ROIG, J. Ciencias Sociales, Geografia e Historia. Limes 1ESO. Vicens-Vives, 2003, pp. 228-243. 
abarcamos toda la historia antigua.

El esquema de examen que vamos a realizar será el siguiente:

- Tartessos y los pueblos colonizadores.

- Íberos.

- Andalucía romana.

- Hispania Visigoda.

A partir del libro presentado anteriormente, tenemos que apreciar ciertos detalles en cuanto al uso determinado que se hace del vocabulario. Esto es, el uso indiscriminado de, por ejemplo, el nombre de Andalucía para todas las etapas históricas: sabemos perfectamente que Andalucía no nace hasta el s. XX, con el referéndum del 28 de febrero de $1980^{8}$. El uso y abuso del nombre de la propia comunidad puede deberse, a nuestro parecer, a dos razones: la primera, sin intenciones perversas, para transmitir la materia en forma más didáctica y de fácil aprendizaje, en vez de componer un texto complejo para definir lo que fue el territorio y lo que ahora es la actual Andalucía; la segunda, de forma intencionada, identificar empecinadamente tierra y pueblo con las culturas que la ocuparon, de tal manera que, a nuestro modo de ver, es ya un principio táctico de la manipulación de la historia, en tanto va logrando dejar un turbio poso de identidad en los estudiantes.

Hay que tener especial cuidado, a la hora de leer un texto de esta naturaleza, ya que podemos caer en una trampa, quizá acordada por los autores, que da a entender que Andalucía ya existía en época prehistórica, antigua o medieval. No sólo en este libro educativo, sino que en muchas de las obras no utilizadas para la enseñanza, identifican la actual Andalucía como un ente que siempre habría existido. Y el primero que toma esta idea viene dada por la confusión del propio Blas Infante en la que trata de asentar una historia para el territorio rechazando la historia "oficial" de España, argumentando que Andalucía procede de Tartessos, y aseverando que Tartessos fue el primer estado andaluz ${ }^{9}$. Es obvio que, utilizando tales términos, se logra un desconcierto que después (prácticas políticas de manual) se trata de menguar y reconducir.

Para abordar el texto de $1^{\circ}$ ESO de Vicens-Vives, vamos a analizar las páginas correspondientes a la Prehistoria, Protohistoria, Historia Antigua de Andalucía, las cuales comprenden desde la 228 a la 243.

El inicio del libro de enseñanza comienza de forma sesgada, tal como creemos nosotros: 'La presencia del ser humano en las tierras de Andalucía

8 RUIZ ROBLEDO, A.: La formación de la Comunidad Autónoma de Andalucía en sus documentos, Prólogo de Manuel Chávez González, Parlamento de Andalucía-Comares, Granada, 2003.

9 INFANTE; Blas: El ideal Andaluz. Estudios preliminares de Tierno Galván y Lacomba. Sevilla. 1915. p. 92. 
es muy antigua...”. Son innumerables las ocasiones que aparece el término de Andalucía para identificarse con la tierra en la que acontecen los hechos. No salimos de la misma página 230 para toparnos con otro párrafo en la que aparece esta identificación, "...las tierras andaluzas alcanzaron un poblamiento mucho mayor que en épocas anteriores...”, o bien: “...en este periodo fue importante la aparición en territorio andaluz del arte rupestre, en el interior de las cuevas". Si pasamos a la siguiente página, nos encontramos con frases tales como "el máximo esplendor de este periodo [el Bronce] está representado en Andalucía por la cultura de El Argar, originaria del Mediterráneo Oriental y establecida en el Sudeste (Almería y Granada) hacia el año 1800 a. C."

Como vemos existe el abuso en la utilización del nombre de Andalucía, algo similar pasa con las provincias, como Almería o Granada. Desde aquí queremos hacer hincapié en que es un término improcedente para etapas anteriores al s. XX. Y, sin pretender negar la existencia de una Prehistoria o alguna otra etapa en Andalucía, incidimos simplemente en un análisis de los usos y abusos terminológicos que se hacen en textos de secundaria, y de la intención de identificar cultura-pueblo-tierra para generar esa huella atávica y patrimonial que individualiza lo andaluz.

Pasaremos al tema más controvertido del temario, que tantos nacionalistas andaluces han preferido proponer, y que es la supuesta cultura de Tartessos; cultura que tantos ríos de tinta ha creado, tanto a favor del Tartessos de Shulten $(1945)^{10}$ o por los que proponen una revisión del asunto histórico, como Wagner (1992) ${ }^{11}$.

El problema está en que el libro de por sí, aun no siendo de investigación, afirma rotundamente la existencia de Tartessos. Acompaña la lección con un mapa ${ }^{12}$, creemos que desproporcionado en cuanto a la extensión de la cultura tartésica, puesto que sitúa a Tartessos como reino, en lo que ocupa la totalidad de la actual Andalucía, Murcia y el sur levantino, dejando libre toda la costa meridional, dominada por la ocupación fenicia. Mapa que, curiosamente, se asemeja al creado por Schulten ${ }^{13}$. Proyección y teorías que ya han sido superadas, aunque se tengan superficialmente en cuenta por ser aquél el padre del orientalismo occidental y el estudio de Tartessos.

Puesto que los estudios sobre Tartessos son numerosos, no entraremos en detalle sobre el origen y evolución de dicha cultura, simplemente nos remitimos a los ya citados, Schulten (1945), o Wagner (1992) y Almagro-

10 SCHULTEN, A.; Tartessos, Madrid, 1945.

11 G. WAGNER, C. "Tartessos en la historiografía: una revisión crítica". La colonización fenicia en el sur de la Península Ibérica: 100 años de investigación, 1992, pp. 81-115

12 Ver imagen $\mathrm{N}^{\circ} 1$.

13 Ver imagen $\mathrm{N}^{\circ} 2$. 
Gorbea $(1996)^{14}$, pero en lo que sí vamos a incidir es en que en el libro de texto estudiado aparece ya taxativamente la capital y el río Tartessos. El primer error consiste "certificar" que la capital tartésica sea la que en el mapa aparece, factor a tener en cuenta puesto que la supuesta capital no ha sido, en realidad, encontrada aún ${ }^{15}$. Y en segundo lugar, el río Tartessos, elemento natural del que también se desconoce la pretendida identificación exacta con el Guadalquivir, Guadiana o el río Tinto ${ }^{16}$, y sobre los que no entraremos en debate pues no es el objetivo en este trabajo. Simplemente queremos dejar bien claro que, si bien sobre Tartessos no dudamos de la existencia de dicha cultura, lo que sí podremos afirmar es que su identificación con el pueblo andaluz es anacrónica, como lo es la afirmación de que su capital se sitúe en la zona de Huelva o quizás en la actual Sevilla, tal como parece en el mapa $n^{\circ} 1$ presentado. También nos hacemos eco de que lo expuesto como más llamativo de esta civilización sean sus tesoros, cuando Tartessos tuvo otra cultura material, para algunos menos excitante, como es la de su extraordinaria cerámica, suficientemente explicada en los estudios de Escaena et alii (1998) ${ }^{17}$ y en los de Amores (1995) ${ }^{18}$.

El problema recae en que dan por hechos ciertos elementos que han sido, y son, muy discutidos en la historiografía europea respecto a Tartessos. En el caso de la capital de dicho reino o la extensión del mismo, en el libro de texto analizado, se dan por ciertas únicamente las teorías de Schulten. No pretendemos desacreditar al autor alemán, pero sí reiteramos que sus teorías han sido superadas, y muchos de los supuestos o incógnitas que no pudo resolver en su tiempo han sido despejados debido los posteriores hallazgos arqueológicos, nuevos estudios, etc.

En cuanto a los pueblos colonizadores, fenicios y griegos, no dedica más de 4 escuetos párrafos de cuatro líneas cada uno. Se limita a comentar que "la colonización fenicia fue la primera en aparecer por la península fundando numerosas factorías, entre otras Cádiz (Gadir), la más antigua de Europa Occidental, y otras en las costas de Málaga (Malaca), Granada (Sexi, hoy Almuñécar) y Almería (Abdera, hoy Adra)". "...El reino de Tartessos en el s. V a.C. comenzó a debilitarse. Un nuevo pueblo colonizador, el cartaginés, sustituía a fenicios y griegos, mientras que desde el interior, los

14 ALMAGRO-GORBEA, M.: Ideología y poder en Tartessos y el mundo ibérico, Madrid, 1996.

15 CARUZ ARENAS, A. "La localización de la ciudad de Tartessos", Tartessos. V Simposium Internacional de Prehistoria Peninsular, Barcelona, 1969. pp. 347-368.

16 FERNÁNDEZ JURADO, J., 1988-89: “Tartessos y Huelva”, Huelva Arqueológica, X-XI, vol. 3, pp. 101-121.

17 ESCACENA, J.L.; DEL RÍO, A.; LUNA, M.A.: "Cerámica tartésica con decoración grabada. Nuevos testimonios” ACC 9, Sevilla, 1998, pp. 9-23.

18 AMORES, F.: "Las cerámicas pintadas estilo Carambolo: una revisión necesaria de su cronología", Tartessos 25 años después, 1968-1993. Jerez de la Frontera, 1995, pp. 159-178. 
pueblos celtas atacaban sus ciudades amuralladas" ${ }^{19}$. Lo que no deja claro tal párrafo es si se refiere a que los celtas atacaban a los tartésicos o a los fenicios y griegos, lo cual es trascendental puesto que la historia cambiaría radicalmente.

Por lo general la literatura nacionalista andaluza se aferra a autores -en los que reconocemos su autoridad en algunos aspectos- para marginar estudios posteriores que aportan novedosas luces, extrapolando tal interés creado en la literatura histórica andaluza de corte nacionalista a los libros de texto de secundaria, originando un leitmotiv recurrente en las obras de corte ideológico que, repetimos, se traslada y plasma de forma reiterativa en las lecciones de los libros de enseñanza, dando cabida a la vigencia de la famosa máxima propagandista "una mentira dicha mil veces, se convierte en verdad"20.

A continuación ya dedica mayor espacio, no mucho más, a las gentes ibéricas del Sur. Vuelve a centrarse en lo que es Andalucía: “Tartessos terminó disgregándose en pequeños reinos independientes, que en Andalucía se conocen como gentes ibéricas del Sur (turdetanos, bastetanos, túrdulos, bástulos, etc.), quienes establecieron estrechas relaciones comerciales con los cartagineses" "21. Ciertamente no hemos encontrado nunca ese término "gentes ibéricas del Sur"; queremos creer que es un recurso lingüístico para hacer más fácil el aprendizaje, pero otra opinión que puede aplicarse a la misma frase es la de una diferenciación propia al resto de la península, procurándose una particularidad como un pueblo diferente al resto, del cual a su vez parecen haber nacido varios pueblos más. Esto otorgaría la peculiaridad de que desde Andalucía se han creado varias culturas a raíz de la tartésica, que no lo negamos, pero reparamos en la curiosa insistencia con la que se subraya este hecho.

Nuevamente la confusión viene dada por la incorporación nominativa que otorga, al menos, la apariencia de ser dos pueblos diferentes, cuando en la realidad son uno, con bastetanos y bástulos, entre otros. Para un mayor estudio sobre estos pueblos ver Ruiz Rodríguez y Molinos Molinos $(1992)^{22}$ y los de Ferrer Albelda y Prados Pérez (2001-2002) ${ }^{23}$. Sobre otras

19 ALBERT, A. et alii. p. 233.

20 SHIRER LAWRENCE, W. "The Emergence of Paul Joseph Goebbels. The Rise and Fall of the Third Reich". New York, 1960. pp. 123-129.

21 ALBERT, A. et alii., Op. cit., p. 234.

22 RUIZ RODRÍGUEZ, A.; MOLINOS MOLINOS, M.: "Los pueblos ibéricos en la Alta Andalucía y el mundo ibérico bastetano" Centro Andaluz de Arqueología Ibérica, 1992. Consultado el día 19 de febrero del 2011 (http://www.tartessos.info/html/alta_andalucia. htm).

23 FERRER ALBELDA, E; PRADOS PÉREZ, E.: “Bastetanos y Bástulo-púnicos. Sobre la complejidad étnica del sureste de Iberia" Studia E. Cuadrado, AnMurcia, 16-17, Murcia, 2001-2002, pp. 273-282. 
culturas como los turdetanos ver Rufete Tomico (2002) ${ }^{24}$; sobre los túrdulos ver Velázquez Jiménez $(1995)^{25}$ y para leer un análisis general de todos los pueblos prerromanos, Salinas de Frías $(2007)^{26}$.

En esta dualidad de pueblos a la que nos referimos, no falto tanto de fuentes como de hipótesis, ya Salinas de Frías comenta que "la misma dualidad que existe entre turdetanos y túrdulos, puede observarse también entre bastetanos y bástulos. Estrabón (III, 1, 7) dice que el peñón de Calpe, una de las columnas de Heracles, se sitúa entre los bastetanos o bástulos, sin diferenciarlos. En III, 4, 1 dice que en la costa entre Calpe y Cartagena «vive la mayoría de los bastetanos, a los que se les suele llamar también bástulos, y una parte de los oretanos». Plinio (III, 4, 19) sitúa a los bástulos en la costa de la Tarraconense, y tras ellos hacia el interior los mentesanos y oretanos". "...Ptolomeo, finalmente, cita quince ciudades de los bastetanos en la Tarraconensis $(2,6,60)$, de las cuales la única que puede identificarse con seguridad es Acci (Guadix). En la costa meridional de la Península sitúa, por otra parte $(2,4,6)$, a los bástulos, llamados «cartaginenses» (Bastuli Poeni), a los que asigna una serie de ciudades bien conocidas como Carteia (Algeciras), el Peñón de Gibraltar (Calpe)...", aunque lo único que les diferenciaría, según Salinas de Frías, "fuese mayor influencia púnica sobre los bástulos que los bastetanos".

En cuanto a la romanización de la actual Andalucía, el libro de texto analizado presenta lacónicamente cuatro páginas ${ }^{27}$. De nuevo podemos caer en el supuesto didáctico del tema sobre la presencia romana en esta comunidad, cuando titula el tema como "Andalucía romana"28, siendo anacrónico el nombre para esta comunidad si nos atenemos a los tiempos reales de la huella romana, tanto en el conjunto de la Península Ibérica como para su parte meridional.

Comenzando con el contenido de la lección, hay un protagonismo de Andalucía en el periodo romano, "Las tierras andaluzas tuvieron un destacado protagonismo en la II Guerra Púnica, [...]...cuando Roma conoció la importancia que el Sur de la Península tenía para Cartago, intentó cortar el apoyo de los pueblos ibéricos y terminar con los establecimientos

24 RUFETE TOMICO, P.: El final de Tartessos y el periodo turdetano en Huelva. Diputación Provincial Huelva, 2002.

25 VELÁZQUEZ JIMÉNEZ, A.; ENRÍQUEZ NAVASCUES, J. J.: “Celtas y Turdulos, la Beturia" Cuadernos emeritenses; Nº , Museo Nacional de Arte Romano, Mérida (Extremadura), 1995.

26 SALINAS DE FRÍAS, M.: Los pueblos prerromanos de la P. Ibérica. Ed. Akal, Madrid, 2007. 27 ALBERT, A. et alii. pp. 236-239.

28 Ibid. p. 236. 
cartagineses en la costa meridional". Como vemos la aparición de Andalucía en las Guerras Púnicas parece importante, no lo negamos, pero la parte meridional de la Península es conocida mucho después de la aparición de los romanos en tierras levantinas.

La aparición de soldados romanos optando por una guerra peninsular contra Cartago no se produce, en principio, por la parte meridional de la Península, sino que se penetra a ella por Ampurias en el 218 a. C. Cneo Cornelio Escipión y Publio Cornerlio Escipión aparecieron por vez primera en tierras ampurdanesas y no por Andalucía, como se quiere ver. No queremos entrar en detalles de la $\mathrm{II}^{\mathrm{a}}$ Guerra Púnica - para ello nos remitimos a otros estudios como el de Mira Guardiola $(2000)^{29}$ o el de Silo Itálico editado por Villalba Álvarez $(2005)^{30}$ para ver el análisis de la penetración romana a la P. Ibérica-.

El territorio de la actual Andalucía surge para los romanos hacia el año 190 a.C. Cuya fecha nos aparece en el siguiente párrafo del temario de la "Andalucía romana": "Los romanos no encontraron apenas resistencia en las comunidades indígenas: en menos de veinte años desplazaron a sus enemigos y se instalaron en suelo andaluz (hacia el año 190 a.C.)"; ..." "Se inició entonces el proceso de romanización, que fue más intenso y temprano en Andalucía que en las demás zonas peninsulares. Roma convirtió este territorio en una provincia: la Bética (Baetica)"31.

Esto en cierto sentido encaja con lo que dice el propio Blas Infante: "Andalucía para Roma no era una "provincia" más. Era una potencia cultural: Andalucía para Roma, en este sentido apolítico, no era provinciana" "32: "Para mí, Bética no supone, por tanto, una nueva cultura, sino una continuación de la anterior". La cultura bética, es, pues, la misma tartesia continuando su desarrollo con distinto nombre y con nuevos instrumentos (...)"33. "(...) Andalucía hizo esa aportación a la civilización grecolatina, siendo, además, o la cuna de esa civilización, o a lo menos, en sus orígenes, uno de los focos más potentes (...)". "Es decir, que Andalucía es la patria de una de las civilizaciones originales más antiguas del mundo, contribuyendo poderosamente a destruir los prestigios del remoto Oriente, en lo moderno tan quebrantados, de cuna de la Humanidad y de la Civilización" 34. Como podemos constatar, tiene cierta similitud con el texto que se muestra a los

29 MIRA GUARDIOLA, M. Á.: Cartago contra Roma: las Guerras Púnicas. Madrid, 2000.

30 ITÁLICO, S.: La Guerra Púnica, editado por Villalba Álvarez, J., ed. Akal. Madrid, 2005.

31 ALBERT, A. et alii, Op. cit. p. 236.

32 INFANTE, Blas, "Fundamento de Andalucía", en RUIZ LAGOS, M., Fundamentos de Andalucía. Blas Infante, Fundación Blas Infante, 1984, p. 258.

33 Ibíd. p. 260.

34 INFANTE, Blas: "Andalucía y el Ideal”; “Capacidad de los autóctonos andaluces", en El Ideal Andalur, op. cit. pp. 57-59, Cap. III. 
escolares en el libro de educación secundaria.

No entraremos en un debate dilatado sobre si las palabras de Blas Infante contienen mayor o menor rigor, pero lo que si podemos adelantar es que en sus obras se evidencia la intencionalidad (por otra parte, recurrente en la retórica de los nacionalismos) de marcar el carácter propio de lo andaluz, del "genio andaluz" 35 como él mismo lo denomina.

En el modo que viene siendo habitual, los libros de texto aplicados a la enseñanza o educación se presentan, acompañando a la lección, un mapa explicativo sobre la extensión u ocupación de la provincia de la Bética romana ${ }^{36}$. En el caso que nos ocupa, dicho mapa es más o menos aproximativo en cuanto a la extensión de la actual Andalucía. Pero lo que nos deja perplejos es que, de las veinte ciudades señaladas en dicho mapa, sean dieciocho las pertenecientes a la actual Andalucía (Córdoba, Cazorla, Jaén, Guadix, Almería, Granada, Málaga, Antequera, Algeciras, Tarifa, Cádiz, Hasta, Carmona, Écija, Sevilla, Fuenteovejuna, Huelva e Itálica), y dos a Extremadura (Fuente de Cantos y Reina). No se citan ciudades correspondientes a la actual provincia de Ciudad Real (Alcázar de San Juan, Almadén, Campo de Criptana...) o de la zona del Algarve portugués (Barrancos, Amareleja...) tal como aparecen en los estudios de Morales Rodríguez (2000) y en el Archivo Epigráfico ${ }^{37}$. Para una mayor exactitud de la provincia de la Bética, el Archivo Epigráfico de la UCM nos ofrece un $\mathrm{mapa}^{38}$ en donde se ven todas las provincias y áreas de la antigua provincia de la Bética y su ocupación, tanto en la actual Andalucía como en parte de Extremadura, Ciudad Real y la frontera con Portugal en la zona del Algarve.

Otro tema que suscita nuestro interés se refiere a la arqueología. Es la cuestión de la batalla de Munda en el 45 a. C., ya que en nuestro libro de texto es citado como uno de los acontecimientos que acaecieron en esta provincia, lo cual, en parte, no es desacertado. Sí queremos incidir en el hecho arriesgado de dar por atinada la ubicación del enfrentamiento entre

35 INFANTE, Blas: El ideal Andaluz: Estudios preliminares de Tierno Galván y Lacomba. Sevilla. 1915. p. 65 y ss.

36 Ver imagen $\mathrm{N}^{\circ} 3$.

37 Para saber más sobre la cantidad de vestigios romanos en toda la Bética romana ver la tesis doctoral de MORALES RODRÍGUEZ, E. Ma. Los municipios Flavios de la Bética. Granada, 2000. Aparte también se puede consultar la ingente cantidad del Archivo Epigráfico de Hispania, sobre las inscripciones encontradas en toda la provincia romana en: http:/ /www. ucm.es/info/archiepi/aevh/mapa.html. Consultado el 21 de febrero de 2011.

38 Ver imagen $\mathrm{N}^{\circ} 4$. 
Julio César contra los seguidores de Pompeyo: es así como nuestro libro de texto da importancia a Montilla y a Andalucía en esta batalla, "durante el siglo I a.C., Andalucía participó en las guerras civiles que pusieron fin a la República en Roma: en la batalla de Munda (Montilla), en el año 45 a. C., Julio César venció definitivamente a los seguidores de Pompeyo. Para entonces la provincia Bética estaba ya muy romanizada"39. Aun teniendo en cuenta que sobre la batalla de Munda se han escrito miles de páginas ${ }^{40}$, los propios autores jamás se pusieron de acuerdo en su ubicación. Parece ser que los historiadores se inclinan por la reciente teoría de que Munda está cerca de Osuna, en Sevilla, y no en Montilla, Córdoba. Hay indicios arqueológicos de una batalla en la primera, cosa que no se ha visto en la segunda a pesar de buscarse afanosamente durante décadas (nos remitimos a la bibliografía citada en nota a pie de página).

Nuestro temario sobre antigüedad termina con la Hispania Visigoda, a la que el libro de texto dedica sucintamente dos páginas ${ }^{41}$. Como sabemos, en el nacionalismo andaluz propiciado por Blas Infante no hubo mucho aprecio al germanismo, a lo europeo; actitud transmitida hoy también, en parte, por los libros de texto. Quizá por ello la presencia vándala y alana, tanto en la Península Ibérica y sobretodo en Andalucía, parece carecer de importancia.

Que Infante omita a los vándalos o niegue que el término de Andalucía provenga del nombre "Vandalusía", podía pertenecer a la discusión filológica. Pero sí queremos remarcar el antigermanismo que Infante plasma de la siguiente manera: "...se ha dicho que tenemos en las venas sangre vándala, y eso no es cierto. Los pueblos andaluces sufrieron sólo durante dieciocho años los desmanes de los bárbaros silingos. Aquella invasión fue sólo una ráfaga asoladora que pasó al África, sin dejar otro vestigio que la huella salvaje de sus rapacidades y depredaciones. El nombre de Andalucía no se debe a Vandalusía, denominación que le dejaron los vándalos, según creen algunos..."42.

Sin embargo, para algunos estudiosos no deja de ser tentadora la hipótesis de que el nombre de Andalucía viene de Vandalusía o Vandalia. Existen varios textos medievales que nos hablan de esta terminología, entre ellos el del poeta Fernando de Herrera (1534-1597), que nos verifica en el soneto de Alonso Ramírez. de Arellano, el recuerdo de lo que fue Vandalia, regada

39 ALBERT, A., op. cit. p. 236.

40 Ver los estudios sobre el tema de DURÁN RECIO V., y FERREIRO LÓPEZ, M., "Acerca del lugar donde se dio la batalla de Munda", Habis, 15, 1984, pp. 229-235 y a su vez los de FERREIRO LÓPEZ, M. "Acerca del emplazamiento de la antigua ciudad de Cárruca”, Habis, 17, 1986, pp. 265-270. O como fuente primaria atribuida a Julio César De Bello Hispaniensi, cap. $36-41$.

41 ALBERT, A., op. cit. pp. 240-241.

42 INFANTE, B., op. cit. Cap. III, p. 95. 
por el río Betis, más tarde renombrado por los árabes como Guadalquivir:

Divino Betis, que por la llanura

de la fértil Vandalia discurriendo,

el estendido campo enriqueciendo,

a tu región das nombre $i$ das frescura

$$
(\ldots)^{43}
$$

Retomando a Blas Infante, se trasladan ideas a nuestro libro de texto, en el que nos encontramos párrafos donde denomina a la cultura visigoda y a su pueblo como bárbaros, con problemas de adaptación o aculturación, sin saber latín, etc.; con joyas, digamos literarias, como: "En el año 411, otro de esos pueblos, los visigodos, que eran aliados de los romanos, acudieron a la Península para expulsar a los invasores. Los vándalos y parte de los alanos pasaron al norte de África; los suevos quedaron arrinconados en Galicia”; "...los visigodos tuvieron problemas de adaptación: hablaban un idioma distinto del latín de los hispanos, practicaban una religión diferente, eran arrianos, y tenían unas leyes y unas costumbres también distintas"; "lentamente los reyes y jefes visigodos fueron aceptando la superior cultura de los hispanorromanos, se emparentaron con ellos y acabaron aprendiendo el latín"; "como los otros reinos germanos, el visigodo también era pobre..."; "San Isidoro de Sevilla con su obra Etimologías, apenas hicieron [intelectuales] otra cosa que recopilar, más mal que bien, el saber de la cultura grecorromana"44. Más allá de las evidencias literales podemos apreciar que, entre líneas, encontramos el argumento antieuropeo o antigermano presente en los textos reproducidos, tanto de Infante como del libro de la editorial Vicens-Vives. Esto se debe a que el sentimiento de Blas Infante y por ende, del nacionalismo andaluz, se condensa, al menos en una primera fase, en "regionalista andaluz, nacionalista español y antieuropeísta", aunque luego, en su segunda coyuntura, sea de conversión de regionalista andaluz a nacionalista andaluz a partir de la Asamblea de Ronda de 1918.

Para concluir este artículo, cuya única pretensión es la del debate que promueva mayor rigor histórico con los elementos que actualmente disponemos, asumiremos que los primeros libros de texto educativo para escolares -históricos, en nuestro caso- tratan de facilitar la comprensión de los alumnos con informaciones básicas y que no son, por tanto, recursos usados para estudios superiores, tanto universitarios como de investigación histórica.

No obstante nos hemos atrevido a dar un paso en el que, acercándonos someramente al contenido, considerásemos la intención del texto en sí. Es

43 HERRERA, F., Poesía castellana original completa, Edit. Cátedra, Madrid, 1985, p. 559. 44 ALBERT, A., op. cit. pp. 240-241. El subrayado o cursiva es del original. 
decir, hemos querido analizar cómo un libro de texto traslada ideas, a través de la tergiversación o manipulación de la historia antigua. Este uso y abuso de poder - parece ser que imprescindibles en las ideologías excesivamente patrióticas-, al inmiscuirse sesgada e ideológicamente en la enseñanza, nos ha llevado esbozar este primer examen sobre la forma de presentarlos a una juventud todavía, lógicamente, carente de criterios.

El comentario sobre el libro de texto mencionado será ampliado en una tesis doctoral donde se hallarán más exhaustivamente analizados varios manuales de enseñanza (referidos a Andalucía y también a otras comunidades), y en la que expondremos que no sólo es un libro o una sola editorial los que tergiversan lo ya conocido y aceptado en las disciplinas históricas. Desestructurar y adaptar la historia con el fin de acomodarla a intereses políticos efímeros e ideologías transitorias, beneficia únicamente a los promotores: en su intento y práctica, serán los escolares, indefensos, quienes sufrirán una perspectiva distorsionada junto a supuestos conocimientos que los mantendrán en inferioridad de condiciones intelectuales. 


\section{IMÁGENES:}

\section{TARTESSOS Y LOS PUEBLOS COLONIZADORES}

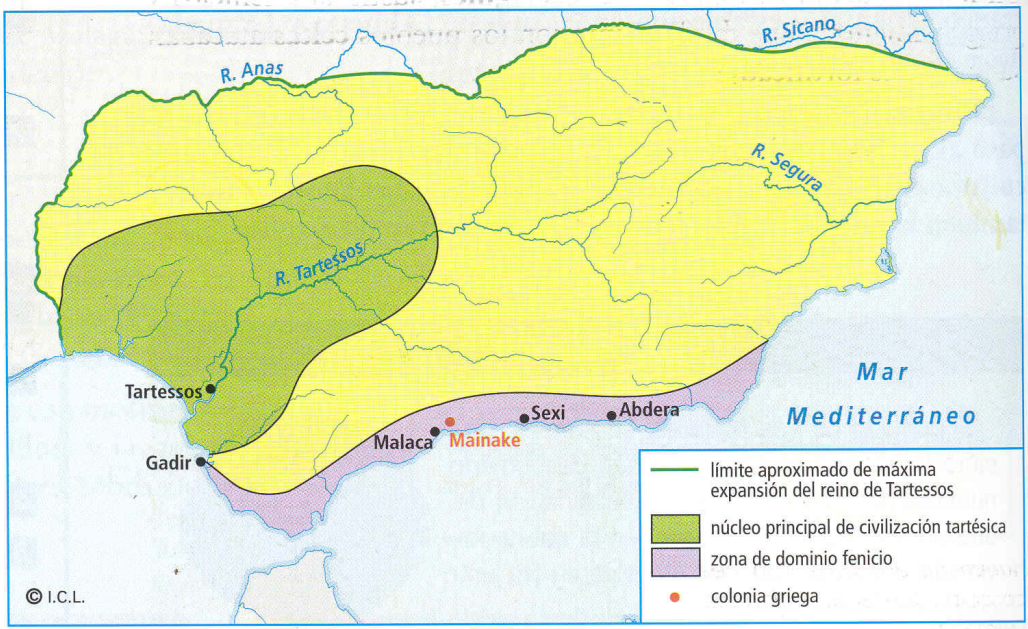

Imagen Nº Mapa de Tartessos según el libro de texto; p. 232. Obsérvese el espacio ocupado por el "reino de Tartessos". ALBET, A.; BENEIAM, P.; MONTERO, C.; GARCÍA, M.; GATELL, C.; ROIG, J. Ciencias Sociales, Geografía e Historia. Limes $1^{\circ} \mathrm{ESO}$. Vicens-Vives, 2003.

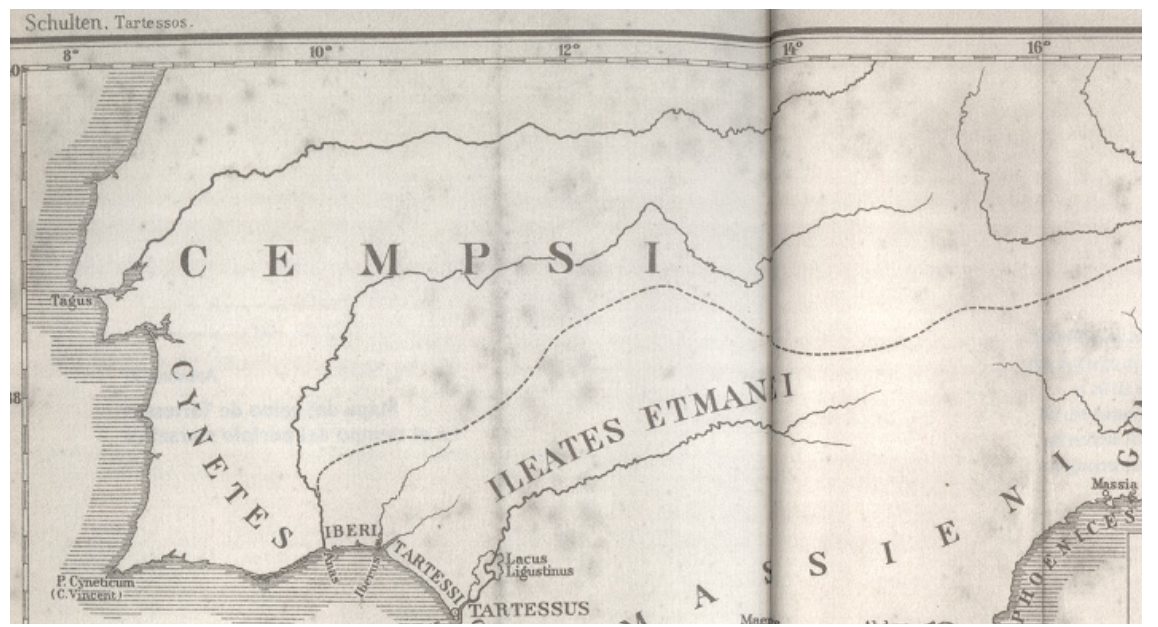

Imagen NoII: Mapa de Tartessos según Schulten. Véase la similitud con nuestro libro de texto analizado y como la imaginación de este autor hacer que esta cultura se expanda más allá de la desembocadura del río Guadalquivir. Fuente: SCHULTEN, A.: Tartessos, Madrid, 1945. 


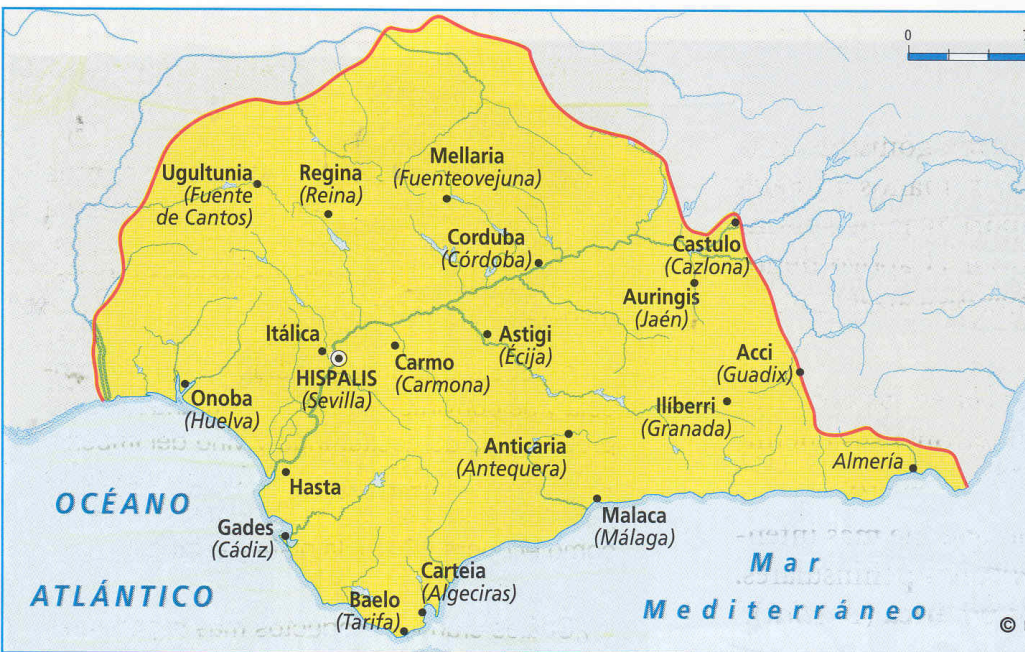

Imagen NoIII: Mapa de la Bética romana. Distíngase la extensión más o menos correcta de la provincia, algo singular en este libro de texto. Fuente: ALBET, A.; BENEIAM, P.; MONTERO, C.; GARCÍA, M.; GATELL, C.; ROIG, J. Ciencias Sociales, Geografía e Historia. Limes $1^{\circ} \mathrm{ESO}$. Vicens-Vives, 2003.

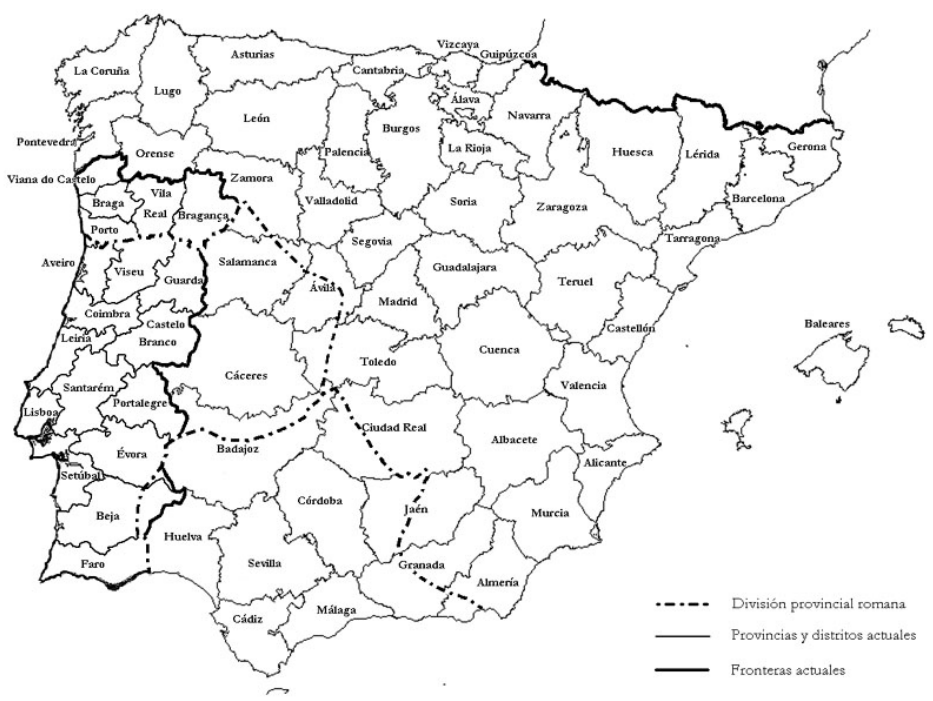

Imagen NoIV: Mapa de la P. Ibérica. Compárese el tamaño de la anterior imagen con esta, las fronteras son similares, excepto que este mapa incluye una pequeña porción de Portugal y Ciudad Real. Fuente: Archivo Epigráfico de Hispania Virtual, http://www. ucm.es/info/archiepi/aevh/mapa.html. 


\section{BIBLIOGRAFÍA:}

ALBET, A.; BENEIAM, P.; MONTERO, C.; GARCÍA, M.; GATELL, C.; ROIG, J. Ciencias Sociales, Geografía e Historia. Limes $1^{\circ} \mathrm{ESO}$. VicensVives, 2003, pp. 228-243.

ALMAGRO-GORBEA, M.: "Ideología y poder en Tartessos y el mundo ibérico", Madrid, 1996.

AMORES, F.: "Las cerámicas pintadas estilo Carambolo: una revisión necesaria de su cronología", Tartessos 25 años después, 1968-1993. Jerez de la Frontera, 1995, pp. 159-178.

CARUZ ARENAS, A. "La localización de la ciudad de Tartessos", Tartessos. V Simposium Internacional de Prehistoria Peninsular, Barcelona, 1969, pp. 347-368.

CORREA, J. A.: "Identidad, cultura y territorio en la Andalucía prerromana a través de la lengua y la epigrafía", en WULFF ALONSO, F., ÁLVAREZ M. (eds.) Identidades, culturas y territorios en la Andalucía prerromana, 2009, Málaga-Sevilla, pp. 273-297.

DURÁN RECIO V., y FERREIRO LÓPEZ, M., “Acerca del lugar donde se dio la batalla de Munda", Habis, 15, 1984, pp. 229-235

ESCACENA, J.L.; DEL RÍO, A.; LUNA, M.A.: “Cerámica tartésica con decoración grabada. Nuevos testimonios” ACC 9, Sevilla, 1998, pp. 9-23. FERNÁNDEZ JURADO, J.: “Tartessos y Huelva", Huelva Arqueológica, X-XI, vol. 3, Huelva, 1988-89, pp. 101-121.

FERREIRO LÓPEZ, M. "Acerca del emplazamiento de la antigua ciudad de Cárruca”, Habis, 17, 1986, pp. 265-270

FERRER ALBELDA, E; PRADOS PÉREZ, E.: “Bastetanos y Bástulopúnicos. Sobre la complejidad étnica del sureste de Iberia" Studia E. Cuadrado, AnMurcia, 16-17, Murcia, 2001-2002, pp. 273-282.

G. WAGNER, C. "Tartessos en la historiografía: una revisión crítica". La colonización fenicia en el sur de la Península Ibérica: 100 años de investigación, Madrid, 1992, pp. 81-115.

GARCÍA NINET, A. "Educación y adoctrinamiento", Periódico Levante, Valencia, 11 de marzo de 2006.

HERRERA, F., Poesía castellana original completa, Edit. Cátedra, Madrid, 1985. HIJANO del Río, M.: "La Historia de Andalucía en los libros de texto", en PORRAS BLANCO, J. (coord.) Independencia, N 39. Mijas (Málaga) 2002. 
--“La cultura andaluza en los libros de texto", Comunicar, marzo, No 14, Colectivo Andaluz para la Educación en Medio de Comunicación, 2000, pp. 153-158.

INFANTE, Blas, "Fundamento de Andalucía”, en RUIZ LAGOS, M., Fundamentos de Andalucía. Blas Infante, Fundación Blas Infante, 1984.

ITÁLICO, S.: La Guerra Púnica, en Villalba Álvarez (ed.), J., ed. Akal. Madrid, 2005.

LACOMBA, J.A., La creación de una disciplina autónoma de Historia y Cultura de Andalucía en el BUP. Un proyecto de didáctica de la asignatura, VI Coloquio Metodológico-didáctico, Hespérides Sevilla, 1987.

MIRA GUARDIOLA, M. Á.: Cartago contra Roma: las Guerras Púnicas. Madrid, 2000.

MOORE, T. W. "Introducción a la Filosofía de la Educación” Cap. 4.- Enseñanza y Educación. Ed. Trillas. 1987. pp. 59-74.

MORALES RODRÍGUEZ, E. Ma . Los municipios Flavios de la Bética. Granada, 2000.

MORENO, I., "La identidad histórica y cultural de Andalucía", Comisión: Andalucía una realidad Multicultural. Proyecto Andalucía en el Nuevo Siglo 1998.

ONIEVA, J. L.: Ortografía y vocabulario para andaluces. Sevilla, 1985.

RUFETE TOMICO, P.: "El final de Tartessos y el periodo turdetano en Huelva” Diputación Provincial Huelva, 2002.

RUIZ MORALES, F.C., "La imagen de Andalucía en los libros de texto", en Actas del VII Congreso sobre el andalucismo histórico, Fundación Blas Infante, Sevilla, 1999, pp. 619-636.

RUIZ ROBLEDO, A.: La formación de la Comunidad Autónoma de Andalucía en sus documentos, Prólogo de Manuel Chávez González, Parlamento de Andalucía-Comares, Granada, 2003.

RUIZ RODRÍGUEZ, A.; MOLINOS MOLINOS, M.: "Los pueblos ibéricos en la Alta Andalucía y el mundo ibérico bastetano" Centro Andaluz de Arqueología Ibérica, 1992. Consultado el día 19 de febrero del 2011. (http://www.tartessos.info/html/alta_andalucia.htm).

SALINAS DE FRÍAS, M.: Los pueblos prerromanos de la P. Ibérica. Ed. Akal, Madrid, 2007.

SCHULTEN, A.; Tartessos. Madrid, 1945. 
SHIRER LAWRENCE, W. "The Emergence of Paul Joseph Goebbels. The Rise and Fall of the Third Reich". New York, 1960. pp. 123-129. TIERNO GALVÁN, E. y LACOMBA J. A.: El ideal andaluz Blas Infante; estudios preliminares. Madrid, 1976.

VELÁZQUEZ JIMÉNEZ, A.; ENRÍQUEZ NAVASCUES, J.J.: “Celtas y Túrdulos, la Beturia" Cuadernos emeritenses; No9, Museo Nacional de Arte Romano, Mérida (Extremadura), 1995. 